\title{
Dilemma and Router of Return Traditional Wushu
}

\author{
Zhang Kun \\ Nanjing Polytechnic Institute Nanjing, Jiangsu 210046, China \\ Email:565076790@qq.com

\begin{abstract}
The demands of returning to traditional Wushu has started again recently. By reading literature, expert interview and logical analysis, this paper specifically illustrates the necessities, practical difficulties and the path of returning to traditional Wushu. It believes that returning to traditional Wushu is a correction to deviant trajectory of Wushu. At the same time, the path to returning to the traditional Wushu has dilemma, such as, the academic research needs to be further in-depth, the breaking tradition of Wushu needs a long time to return and reset, competitive wushu have a stigma stand at the height of modernity and need to overcome the Path-Dependence of athletics Wushu. To achieve the goal of returning to traditional Wushu, it needs to multiple levels of path.
\end{abstract}

Keywords: traditional Wushu, return, dilemma, route

\section{Preface}

Since the 1990s, the academic circle has issued the call of "Wushu returns to tradition", which changes with the development of traditional Wushu and competitive Wushu. The return of Wushu to tradition refers to the return of Competitive Wushu. Its essence is to advocate the return of Wushu to the cultural tradition of Wushu, that is, to refer to the Wushu tradition inherited by Chinese Traditional Wushu for thousands of years, or to return comprehensively or critically. [1]

In this context, we need to answer the following questions urgently: why does the development of Chinese Wushu need to return to tradition? What practical difficulties will Wushu encounter when it returns to the traditional ideal? How can Wushu return to tradition? Therefore, this paper will explain the necessity of Wushu's return to the tradition, the realistic predicament and its transcendental path in turn.

\section{On the necessity of Wushu returning to tradition}

\subsection{The value orientation of Wushu deviates from the essence of fighting}

If we say that "the history of Wushu development is actually the history of value selection", then the biggest problem of Wushu is that it deviates from the essence of fighting in value orientation, which leads to the deviation of Wushu development direction. Objectively speaking, the modernization of Wushu, or the development of sports, is an important driver of this deviation. It is against the law of Wushu's own development to withdraw the connotation of

fighting in Wushu, and the development of Wushu is forced to take a deviated road. Therefore, the loss of the essential value of Wushu has become the main factor of the predicament of Wushu development. [2]

\subsection{The form of Wushu deviates from the national characteristics}

The value of traditional martial arts lies in that it transcends the fighting violence with the spirit of the highest value pursuit of "technology goes into Tao", and provides unique cultural elements, cultural spirit and cultural value for the world martial arts culture. However, martial arts, out of the need of modernization, embarked on the road of imitating western sports culture. Because Wushu fails to make a full comparative analysis of the value of Chinese and western sports culture, in the process of imitating western sports culture, Wushu gives up its own national characteristics and advantages.

\subsection{There is no doubt that the biggest difference between Chinese Wushu and other}

Nations in the world lies in the rich cultural connotation of Chinese Wushu. However, who moved the tradition of martial arts, making it inevitable to hurt the traditional martial arts. It is generally believed that with the powerful power of western economy, the modern Olympic culture is the sports culture mode that dominates the world. Under the pressure of such a strong "cultural potential difference", all cultural circles with different verve from western culture are forced to make adaptive response and adjustment, some even hesitate to "cut their feet to fit their feet" to achieve the modernization transformation of national sports culture. The traditional martial arts just in the process of modernization and 
transformation dispelled the tradition of martial arts excessively. [3]

\section{THE PREDICAMENT OF WUSHU RETURNING TO TRADITION}

\subsection{The academic research of Wushu returning to tradition needs further study}

Although the advocates of Wushu return didn't ignore the need of Wushu return to tradition, the academic research of Wushu return to tradition needs to be further in-depth and careful analysis of tradition, however, the relevant research is slightly insufficient, and most of it is the interpretation of principles. It can be seen that although the advocates of Wushu returning to the tradition realize that they should not only have the cultural self-control function of tradition, but also notice that the inertia of tradition inevitably blocks Wushu. The current advocates of Wushu's return to tradition do not give a specific plan on how to separate out the inappropriate part of tradition and keep the essence of tradition. [4]

\subsection{Broken martial arts tradition needs a long time to return and reset}

After the baptism of the May 4th New Culture Movement, science, once praised by Lu Xun as the "holy light", played the role of "judge" in the fierce collision of the two thoughts of "local and foreign sports", so science gradually began to play an important guiding role. The traditional Wushu has taken a scientific step. In the literature of the Republic of China, it has been advocated to "estimate the value of Chinese art" from multiple perspectives such as mathematics, heavy learning, mechanics, physiology and psychology Wu Zhiqing, a famous sportsman, pointed out that Wushu is also "an element of new civilization" and "a science". In a word, the scientific spirit of this period has become a strong social psychological demand. Traditional Wushu has been converted to Western science, and the process of the transformation of Wushu theory from the traditional philosophy paradigm to the scientific one has been accelerated. Under the background of this era, ancestor worship and family opinions are criticized as bad habits that hinder the development of Wushu. In addition, driven by the strong spread of science, the following educational concepts and methods are refreshing. The way of inheriting teachers and apprentices is slightly backward and gradually abandoned.

\section{THE WAY OF WUSHU RETURNING TO TRADITION}

\subsection{On the level of martial arts academic research, further strengthen the research on reinterpretation of traditional value of martial arts}

Although the return of martial arts to tradition does not mean that we should inherit the martial arts tradition in an all-round way, it is also an important rational premise to keep a certain degree of calm in the tradition of martial arts. After all, tradition is a double-edged sword, especially the coexistence of the traditional martial arts, which has both positive and negative effects. Therefore, it is necessary to "Disenchantment" the irrational elements in Wushu tradition, that is, to choose and transform Wushu tradition, so as to give full play to the "positive energy" of Wushu tradition and to make Wushu tradition be combed, understood and elucidated. However, the so-called "essence" and "dross" in the tradition will also have different understanding with the development of the times. Therefore, in the process of recovering Wushu tradition, we should also strengthen the research work of reinterpretation of traditional values. At present, scholars have made some important theoretical achievements. In addition, in recent years, the relevant research also shows that the attention to the martial arts tradition has been from the theory to the specific dimensions of the martial arts tradition. In addition, Ma Wenyou examined the traditional belief that all walks of life in the traditional society generally adhere to the principle of respecting teachers. He believed that respecting teachers is "the code of conduct for martial artists, which has always guided martial arts along the right track." It can be seen from the above research conclusions that the research on the current social value of Wushu tradition will help people to further understand the value of tradition, thus laying an important theoretical foundation for Wushu to return to tradition. [5]

\subsection{On the practical level of traditional Wushu, restore the cultural confidence of traditional Wushu}

In the face of the strong spread of heterogeneous and other culture, the current traditional Wushu is obviously lack of cultural confidence. In fact, culture coexists in many ways. It is difficult for a culture without personality to have the charm and strength of inheritance and communication. Even judo, which completes the modernization transformation well, still insists on the idea that "the constant is the eternal new" This kind of self-confidence comes from the persistence and deep understanding of the tradition, as well as the resulting sense of identity. Therefore, traditional martial arts should first restore cultural confidence, not only learn from foreign cultures, but also look back to their own history, repair the broken link between tradition and modern, so that martial arts continue to absorb the traditional nutrients, and gain new 
momentum in repairing the broken tradition, so that the future path of martial arts will be more stable. [6]

\subsection{On the level of martial arts management, the path dependence of martial arts development}

With the change of society and culture, traditional Wushu has lost the space to verify its fighting effect. Therefore, the intention of Wushu's return to tradition is not only to restore the traditional Wushu's sports form, but also to restore the traditional Wushu's etiquette norms, organizational forms, training concepts and methods, as well as the operation mode of the system of laws and regulations. However, after years of development, competitive Wushu has become a new tradition. Therefore, the overlapping of the old and the new traditions has inadvertently set an obstacle for Wushu to return to the tradition. In this regard, the martial arts management level needs to return to the local cultural significance with the determination of "all return to zero", format the existing martial arts development pattern, and abide by the principle and position of cultural subjectivity.

\section{CONCLUSION}

Wushu's return to tradition is not to copy the tradition, not to stick to the past, but to re reference the tradition, and then adjust the modernization of Wushu, and re extract the essence of modern culture from the stubborn, closed and conservative cultural ore. Therefore, the future development direction of Wushu should be the process of "reduction" to the traditional and "evolution" to the modern. In a word, Wushu's return to tradition is not to stick to tradition, but to fully respect the traditional self regeneration mechanism, not to simply maintain the original cultural form, but to complete the re integration and expression of Wushu's tradition in the context of modernity.

\section{REFERENCES}

[1] Li long. On Traditional Wushu and Wushu tradition[J]. Journal of Nanjing Institute of physical education 2013,27 (6): 192

[2] Cai Yuefei. On the return and contemporary value of traditional Wushu [J]. Journal of Wuhan Institute of physical education, 2015,49 (8): 42

[3] Lu Xiaohei, Zhu Dami, Wu Song. "Seemingly" and "not": Traditional Wushu and Wushu tradition [J]. Journal of Tianjin Institute of physical education, 2009,24 (4): 347

[4] Qin Zilai. Research on development strategy of traditional Wushu [J]. Journal of Chengdu Institute of physical education, 2008,34 (1): 39
[5]Dai xiao ping The reform of Wushu competitive routine should meet the requirements of the Olympic Games[J]Journal of Wuhan Institute of Physical Education; JWIPE;2001,35(1):58.

[6]Wang gang The strategy of Wushu Internationalization: maintaining tradition and surpassing tradition[J].China Sports Science and technology2005,41 (4) : 17-20. 